Pacific Journal of Mathematics

SOME REMARKS ON A PAPER OF ARONSZAJN AND 


\title{
SOME REMARKS ON A PAPER OF ARONSZAJN \\ AND PANITCHPAKDI
}

\author{
MELVIN HENRIKSEN
}

In the paper of the title [1], a number of problems are posed. Negative solutions of two of them (Problems 2 and 3) are derived in a straightforward way from a paper of L. Gillman and the present author [2].

Motivation will not be supplied since it is given amply in [1], but enough definitions are given to keep the presentation reasonably selfcontained.

1. A Hausdorff space $X$ is said to satisfy $\left(Q_{\mathfrak{m}}\right)$, where $m$ is an in finite cardinal, if, whenever $U$ and $V$ are disjoint open subsets of $X$ such that each is a union of the closures of less than $m$ open subsets of $X$, then $U$ and $V$ have disjoint closures. In particular, a normal (Hausdorff) space $X$ satisfies $\left(Q_{\aleph_{1}}\right)$ if and only if disjoint open $F_{\sigma}$-subsets of $X$ have disjoint closures. (For, an open set that is the union of less than $\tau_{1}$ closed sets is a fortiori an $F_{\sigma}$. Conversely if $U$ is the union of countably many closed subsets $F_{n}$, then since $X$ is normal, for each $n$ there is an open set $U_{n}$ containing $F_{n}$ whose closure is contained in $U$. Thus $U$ is the union of the closures of the open sets $U_{n}$.) In Problem 3 of [1], it is asked if every compact (Hausdorff) space satisfying $\left(Q_{\mathfrak{m}}\right)$ for some $\mathfrak{m}>\widehat{\psi}_{0}$ is necessarily totally disconnected, and it is remarked that this is the case if the first axiom of countability is also assumed.

If $X$ is a completely regular space, let $C(X)$ denote the ring of all continuous real-valued functions on $X$, and let $Z(f)=\{x \in X: f(x)=0\}$, let $P(f)=\{x \in X: f(x)>0\}$, and let $N(f)=P(-f)$. As usual, let $\beta X$ denote the Stone-Čech compactification of $X$. If every finitely generated ideal of $C(X)$ is a principal ideal, then $X$ is called an $F$-space. The following are equivalent.

(i) $X$ is an $F$-space.

(ii) If $f \in C(X)$, then $P(f)$ and $N(f)$ are completely separated [2, Theorem 2.3].

(iii) If $f \in C(X)$, then every bounded $g \in C(X-Z(f))$ has an extension $\bar{g} \in C(X)$ [2, Theorem 2.6].

A good supply of compact $F$-spaces is provided by the fact that if $X$ is locally compact and $\sigma$-compact, then $\beta X-X$ is an $F$-space [2, Theorem 2.7].

Received April 1, 1957. In revised form April 29, 1957. This paper was written while the author was an Alfred P. Sloan fellow. 
We remark first that a normal (Hausdorff) space $X$ satisfies $\left(Q_{\aleph_{1}}\right)$ if and only if it is an $F$-space.

For, suppose first that $X$ is an $F$-space, and let $U, V$ be disjoint open $F_{\sigma}$-subsets of $X$. Since $X-(U \cup V)$ is a closed $G_{\delta}$ in a normal space, there is a bounded $f \in C(X)$ such that $Z(f)=X-(U \cup V)$. Hence by (iii), there is a $\bar{g} \in C(X)$ such that $\bar{g}[U]=0$ and $\bar{g}[V]=1$. In particular, $U$ and $V$ have disjoint closures, so $X$ satisfies $\left(Q_{\mho_{1}}\right)$. Conversely let $X$ satisfy $\left(Q_{\Im_{1}}\right)$, and let $f \in C(X)$. Then $P(f)$ and $N(f)$ are disjoint open $F_{\sigma}$-subsets of $X$, which by $\left(Q_{\aleph_{1}}\right)$ have disjoint closures. So, by Urysohn's lemma, $P(f)$ and $N(f)$ are completely separated. Thus $X$ is an $F$-space by (ii).

Compact connected $F$-spaces exist. In particular it is known that if $R^{+}$denotes the space of nonnegative real numbers, then $\beta R^{+}-R^{+}$is such a space [2, Example 2.8]. Hence Problem 3 of [1] has a negative solution.

We remark finally that if the first axiom of countability holds at a point of an $F$-space, then the point is isolated [2, Corollary 2.4]. In particular, every compact $F$-space satisfying the first axiom of countability is finite.

2. In Problem 2 of [1], it is asked (in different but equivalent language) if for every totally disconnected compact space $X$ satisfying $\left(Q_{\mathfrak{m}}\right)$ for some $m>\widehat{\kappa}_{0}$, the Boolean algebra $B(X)$ of open and closed subsets of $X$ has the property that every subset of less than $m$ elements has a least upper bound. A lattice is said to be (conditionally) $\sigma$-complete if every bounded countable subset has a least upper bound and a greatest lower bound. In view of the above (and since every subset of $B(X)$ is bounded), in case $n=\kappa_{1}$, the problem asks if for every compact totally disconnected $F$-space $X$, the Boolean algebra $B(X)$ is $\sigma$-complete.

In [3, Theorem 18], it is shown that if $X$ is compact and totally disconnected, then $B(X)$ is $\sigma$-complete if and only if $C(X)$ is $\sigma$-complete (as a lattice). It is noted in [2, Theorem 8.3, f.f.] that for a completely regular space $Y$, the lattice $C(Y)$ is $\sigma$-complete if and only if $f \in C(Y)$ implies $\bar{P}(f)$ and $\bar{N}(f)$ are disjoint open and closed subsets of $Y(\bar{P}(f)$ denotes the closure of $P(f)$ ). It is easily seen that $Y$ has this latter property if and only if $\beta Y$ has [2, Lemma 1.6].

In [2, Example 8.10], an example is given of a completely regular space $X$ such that $\beta X$ is a totally disconnected $F$-space, and such that $C(X)$ is not $\sigma$-complete. By the above, it follows that $B(\beta X)$ yields a negative solution to Problem 2.

We remark also (as was pointed out by J. R. Isbell) that if $N$ denotes the countable discrete space, then $\beta N-N$ is also a totally disconnected compact $F$-space such that $B(\beta N-N)$ is not $\sigma$-complete. The 
former assertion follows easily from the remarks in $\S 1$, and the latter follows from the fact that $B(\beta N-N)$ is isomorphic to the Boolean algebra of all subsets of $N$ modulo the ideal of finite subsets of $N$ (under the correspondence induced by sending a subset of $N$ to the intersection of its closure in $\beta N$ with $\beta N-N$ ). It is easily verified that this latter Boolean algebra is not $\sigma$-complete.

\section{REFERENCES}

1. N. Aronszajn and P. Panitchpakdi, Extensions of uniformly continuous transformations and hyperconvex metric spaces, Pacific J. Math. 6 (1956), 405-439.

2. L. Gillman and M. Henriksen, Rings of continuous functions in which every finitely generated ideal is principal, Trans. Amer. Math. Soc. 82 (1956), 366-391.

3. M. H. Stone, Boundedness properties in function lattices, Canadian J. Math. 1 (1949), $176-186$.

The Institute For Advanced Study 



\title{
PACIFIC JOURNAL OF MATHEMATICS
}

\section{EDITORS}

H. L. RoYden

Stanford University

Stanford, California

\section{R. A. Beaumont}

University of Washington

Seattle 5 , Washington
A. L. Whiteman

University of Southern California

Los Angeles 7, California

E. G. Straus

University of California

Los Angeles 24, California

\section{ASSOCIATE EDITORS}

\author{
E. F. BECKENBACH \\ C. E. BURGESS \\ M. HALL \\ E. HEWITT
}
A. HORN
V. GANAPATHY IYER
R. D. JAMES
M. S. KNEBELMAN

L. NACHBIN

I. NIVEN

T. G. OSTROM

M. M. SCHIFFER
G. SZEKERES

F. WOLF

K. YOSIDA

\section{SUPPORTING INSTITUTIONS}

\author{
UNIVERSITY OF BRITISH COLUMBIA \\ CALIFORNIA INSTITUTE OF TECHNOLOGY \\ UNIVERSITY OF CALIFORNIA \\ MONTANA STATE UNIVERSITY \\ UNIVERSITY OF NEVADA \\ OREGON STATE COLLEGE \\ UNIVERSITY OF OREGON \\ UNIVERSITY OF SOUTHERN CALIFORNIA
}

Mathematical papers intended for publication in the Pacific Journal of Mathematics should be typewritten (double spaced), and the author should keep a complete copy. Manuscripts may be sent to any of the editors. All other communications to the editors should be addressed to the managing editor, E. G. Straus at the University of California, Los Angeles 24, California.

50 reprints per author of each article are furnished free of charge; additional copies may be obtained at cost in multiples of 50 .

The Pacific Journal of Mathematics is published quarterly, in March, June, September, and December. The price per volume (4 numbers) is $\$ 12.00$; single issues, $\$ 3.50$. Back numbers are available. Special price to individual faculty members of supporting institutions and to individual members of the American Mathematical Society: $\$ 4.00$ per volume; single issues, $\$ 1.25$.

Subscriptions, orders for back numbers, and changes of address should be sent to Pacific Journal of Mathematics, 2120 Oxford Street, Berkeley 4, California.

Printed at Kokusai Bunken Insatsusha (International Academic Printing Co., Ltd.), No. 10, 1-chome, Fujimi-cho, Chiyoda-ku, Tokyo, Japan.

PUBLISHED BY PACIFIC JOURNAL OF MATHEMATICS, A NON-PROFIT CORPORATION

The Supporting Institutions listed above contribute to the cost of publication of this Journal, but they are not owners or publishers and have no responsibility for its content or policies. 


\section{Pacific Journal of Mathematics}

\section{Vol. 7, No. 4 \\ April, 1957}

Robert Geroge Buschman, A substitution theorem for the Laplace

transformation and its generalization to transformations with

symmetric kernel .

S. D. Conte, Numerical solution of vibration problems in two space variables ...................................... 1535

Paul Dedecker, A property of differential forms in the calculus of variations ......................................... 1545

H. Delange and Heini Halberstam, A note on additive functions . . . . . . . 1551

Jerald L. Ericksen, Characteristic direction for equations of motion of non-Newtonian fluids ................................. 1557

Avner Friedman, On two theorems of Phragmén-Lindelöf for linear elliptic and parabolic differential equations of the second order ........... 1563

Ronald Kay Getoor, Additive functionals of a Markov process . . . . . . . . . 1577

U. C. Guha, $(\gamma, k)$-summability of series . . . . . . . . . . . . . . . . . . 1593

Alvin Hausner, The tauberian theorem for group algebras of vector-valued functions ...................................... 1603

Lester J. Heider, $T$-sets and abstract $(\mathrm{L})$-spaces ................. 1611

Melvin Henriksen, Some remarks on a paper of Aronszajn and

Panitchpakdi........................................ 1619

H. M. Lieberstein, On the generalized radiation problem of A. Weinstein ... 1623

Robert Osserman, On the inequality $\Delta u \geq f(u) \ldots \ldots \ldots \ldots \ldots \ldots \ldots . \ldots 1641$

Calvin R. Putnam, On semi-normal operators . . . . . . . . . . . . . . . . . . 1649

Binyamin Schwarz, Bounds for the principal frequency of the

non-homogeneous membrane and for the generalized Dirichlet integral...

Edward Silverman, Morrey's representation theorem for surfaces in metric

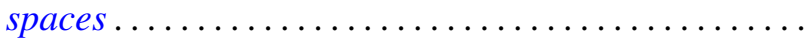

V. N. Singh, Certain generalized hypergeometric identities of the Rogers-Ramanujan type. II .

R. J. Smith, A determinant in continuous rings 1701

Drury William Wall, Sub-quasigroups of finite quasigroup 1711

Sadayuki Yamamuro, Monotone completeness of normed semi-ordered linear spaces.

C. T. Rajagopal, Simplified proofs of "Some Tauberian theorems" of Jakimovski: Addendum and corrigendum ............

N. Aronszajn and Prom Panitchpakdi, Correction to: "Extension of uniformly continuous transformations in hyperconvex metric spaces"...................................

Alfred Huber, Correction to: "The reflection principle for polyharmonic functions" 